\title{
The Comparative Study of Fatigue Crack Propagation Experiment and Computer Simulation on the Component Materials for the Crane Life Remained
}

\author{
Sangyeol Kim ${ }^{1}$, Hyungsub Bae ${ }^{1}$, Myeongkwan Park ${ }^{1}$, Seongsoo Kim², Hanshik Chung ${ }^{2}$, \\ Heekyu Choi ${ }^{3}$
}

\begin{abstract}
${ }^{1}$ School of Mechanical of Engineering, Pusan National University, Busan, Korea; ${ }^{2}$ Department of Precision \& Mechanical Engineering and Eco-Friendly Heat \& Cold Energy Mechanical Research Team, Gyeongsang National University, Gyeongnam, Korea; ${ }^{3}$ School of Nano \& Advanced Materials Engineering, Changwon National University, Gyeongnam, Korea.

Email: hkchoi99@changwon.ac.kr
\end{abstract}

Received November $24^{\text {th }}, 2010$; revised December $13^{\text {th }}, 2010$; accepted January $10^{\text {th }}, 2011$.

\begin{abstract}
This study presents fatigue crack propagation experiments and the simulation used to estimate the life remaining in a crane that is currently in use at a port. The fatigue crack propagation experiments were performed by an Instron 8516 fatigue testing machine and the simulation was performed using the AFGROW software. The simulation results indicated that the critical size of the crack in the upper flange surface of the main jib was $107.4 \mathrm{~mm}$ and that it would take 818000 cycles to reach that point. If the main jib of the crane undertakes 28800 cycles per annum then its remaining lifespan should be 28.4 years.
\end{abstract}

Keywords: Crane, Fatigue Crack Propagation, Computer Simulation, Crane Life Remained

\section{Introduction}

The cracks in a crane installed in a port are propagated by the repeated operation of the crane over a long period of time. A crane may fail, causing a serious accident, if a crack exceeds its critical size. The analysis of fatigue crack propagation is the most important factor in the analysis of the stability and lifespan of the crane but it may require time and expense to investigate it experimentally. Computer simulation is especially useful for studying the flow of granular assemblies or powders in cases where it is difficult to obtain detailed results by direct experimentation [1-3]. Hence, in order to be efficient, the fatigue crack propagation software should estimate the remaining life of the crane experimentally and by simulation. The fatigue crack can be analyzed by non-destructive testing of the main jib, which is subject to severe vibration and fatigue [4]. The critical size of the crack in the main jib can be calculated using the material constants which have been derived experimentally and from the constant amplitude crack propagation curve, crack size-life data and curve using the AFGROW crack propagation software. The crane's remaining lifespan can be deduced from the simulation results for the main jib [5].

\section{Theoretical Background}

Most of the current research on crack propagation uses the widely accepted Paris Equation [6].

In this equation

$$
\mathrm{d} a / \mathrm{d} N=C(\Delta K)^{m}
$$

where $C$ and $\mathrm{m}$ are material constants, and $\Delta K$ is the stress intensity range $K_{\max }-K_{\min }$.

$$
\Delta K=f(g) \Delta \sigma \sqrt{\pi a}
$$

where $f(g)$ is the correction factor that depends on the geometry of the specimen and the crack, $\Delta \sigma\left(\sigma_{\max }-\sigma_{\min }\right)$ and a is the crack size. Substituting into the Paris equation yields

$$
\mathrm{d} a / \mathrm{d} N=C(f(g) \Delta \sigma \sqrt{\pi a})^{m}
$$

Separating variables and integrating gives 


$$
\begin{aligned}
N_{f} & =\int_{a_{i}}^{a_{f}} \frac{\mathrm{d} a}{C(f(g) \Delta \sigma \sqrt{\pi a})^{m}}=\frac{\mathrm{d} a}{C(f(g) \Delta \sigma \sqrt{\pi})^{m}} \int_{a_{i}}^{a_{f}} a^{\frac{-m}{2}} \\
& =\frac{2}{(m-2) C(f(g) \Delta \sigma \sqrt{\pi a})^{m}}\left(\frac{1}{a_{i}^{(m-2) / 2}}-\frac{1}{a_{f}^{(m-2) / 2}}\right)
\end{aligned}
$$

where, $a_{i}$ is the initial crack size and $a_{f}$ is the final crack size which must be evaluated as follows.

$$
\begin{gathered}
K=f(g) \Delta \sigma \sqrt{\pi a} \\
a_{f}=\frac{1}{\pi}\left(\frac{K_{C}}{\sigma f(g)}\right)^{2}=\left(\frac{K_{C}}{1.12 \sigma_{\max }}\right)^{2}
\end{gathered}
$$

$K$ is fracture toughness and $\sigma$ is the remote stress applied to the component.

\section{Fatigue Crack Propagation Experiment and Simulation}

Figure 1(a) shows a luff crane that has been in operation at a port for 20 years. The specification of the crane is: capacity 40 ton, weight 466 ton, height $45 \mathrm{~m}$, rail span 20 $\mathrm{m}$, maximum working radius of jib $33 \mathrm{~m}$ and minimum working radius of jib $9 \mathrm{~m}$. Figure 1(b) shows the crane modeled by the STAAD.Pro 2004 structural analysis software [7]. The fatigue stress of the main jib was derived from the basic loads and load combinations based on Table 1 [8-11].

\subsection{Experiment}

The remaining lifetime of the crane can be estimated experimentally with the fatigue crack found by non-destructive testing of the main jib, which receives severe vibration and fatigue. The compact-tension (CT) test ASTM A36 specimen was made in accordance with ASTM E647-95a [12] and used to analyze the fatigue crack found in the main jib of the crane. The specimen was as thick as the main jib $(15 \mathrm{~mm})$. The constant amplitude crack propagation data, $\mathrm{d} a / \mathrm{d} N-\Delta K$ curve and material constants $\mathrm{C}$ and $\mathrm{m}$ were derived from the fatigue crack propagation experiment using an Instron 8516 machine. $\mathrm{C}$ and $\mathrm{m}$ are the most effective factors in the Paris equation as the fatigue crack propagation equation can be derived from the propagation experiment. The constant amplitude crack propagation curve, crack size-life diagram and $\mathrm{d} a / \mathrm{d} N-\Delta K$ curve were calculated using the governing equations of fatigue crack propagation based on an adaptation of $\mathrm{C}$ and $\mathrm{m}$, which were derived experimentally.

An ASTM A36 CT specimen was used in accordance with the ASTM E647-95a code with the following dimensions: thickness $15 \mathrm{~mm}$, a (crack starter notch) 10.16 $\mathrm{mm}, \mathrm{W} 50.8 \mathrm{~mm}$ and a/W 0.20 with a chevron notch to

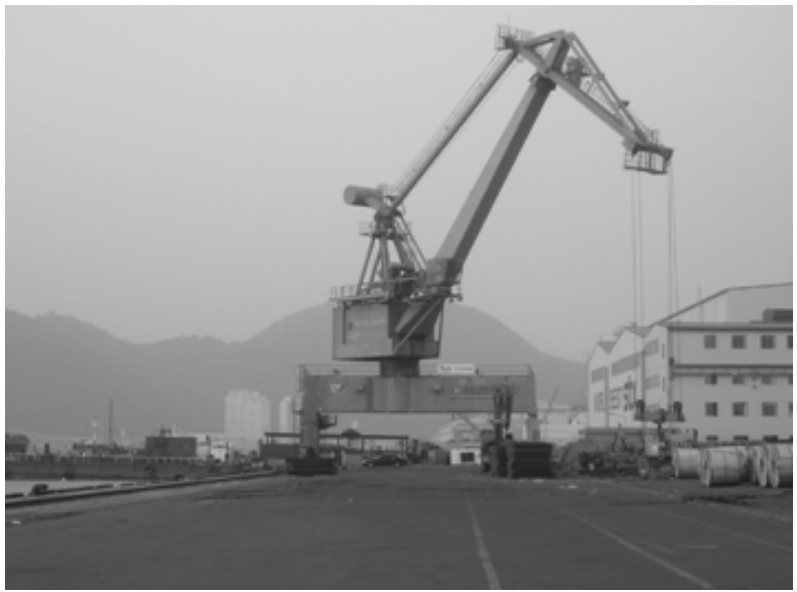

(a)

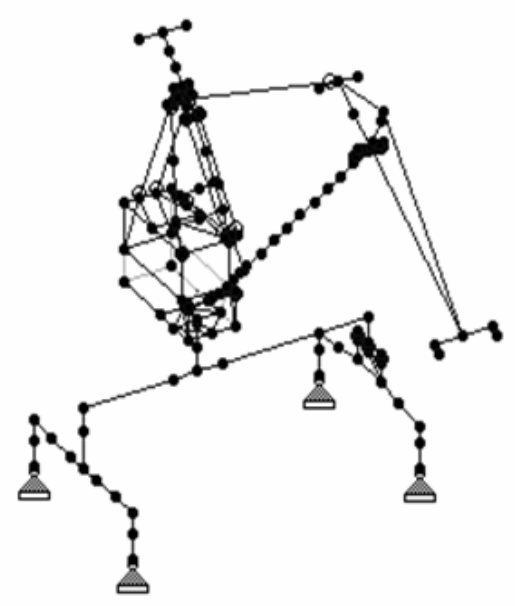

(b)

Figure 1. (a) General view of level luffing crane in port; (b) structural model showing maximum working radius.

Table 1. Specification of crane modeled.

\begin{tabular}{lll}
\hline Item & Data & Remark \\
\hline Rate load & 40 ton & \\
Weight & 466 ton & \\
Height & $45 \mathrm{~m}$ & \\
Rail span & $20 \mathrm{~m}$ & with rated load \\
Hoisting speed & $30 \mathrm{~m} / \mathrm{min}$ & \\
Luffing speed & $40 \mathrm{~m} / \mathrm{min}$ & \\
Slewing speed & $1 \mathrm{rpm}$ & allowable \\
Traveling speed & $25 \mathrm{~m} / \mathrm{min}$ & allowable \\
Sea side wheel load & $30 \mathrm{ton} /$ wheel & \\
Land side wheel load & 30 ton/wheel & \\
Maximum working radius & $33 \mathrm{~m}$ & \\
Minimum working radius & $9 \mathrm{~m}$ & \\
\hline
\end{tabular}


cause a smooth crack in the tip of the crack $[13,14]$ (see Figure 2).

Figure 3 shows the equipment used for this experiment. Figure 3(a) shows the fatigue crack propagation experimental system with 10ton capacity An Instron fatigue experimental machine and servo-hydraulic testing machine were used to operate the actuator in fatigue experimental machine. The frequency is $10 \mathrm{~Hz}$ constant amplitude loading with stress ratio $\mathrm{R}=0.1$ at room temperature, as specified in the ASTM E647-95a code. Figure 3(b) shows the connections and terminal box for the fatigue crack propagation experiment. The direct current potential drop (DCPC) system is shown in Figure 3(c). Figure 3(d) shows the traveling microscope used to observe and measure the cracking of the surface.

\subsection{Simulation}

The main jib is $15 \mathrm{~mm}$ thick and $1,590 \mathrm{~mm}$ wide. The fatigue crack propagation simulation is used to calculate the constant amplitude crack propagation data, crack size-life data and $\mathrm{d} a / \mathrm{d} N-\Delta K$ curve, using the material constants $\mathrm{C}=5.11 \times 10^{-11}$ and $\mathrm{m}=2.260$ [12] which have been derived experimentally. The input data to the crack propagation software is: $K_{I C}, 70 \mathrm{ksc} \sqrt{\mathrm{in}}$, modulus of longitudinal elasticity 206,843 MPa, yield stress 295.7 MPa $\left(30.17 \mathrm{~kg} / \mathrm{mm}^{2}\right)$, Poisson's ratio $=0.33, \mathrm{R}=0.1$, and the stress multiplication factor $=117.6 \mathrm{MPa}(1,200$ $\mathrm{kg} / \mathrm{cm}^{2}$ ) with constant amplitude loading.

The NASGRO equation, which has been utilized in the fatigue growth estimation program at national aeronautics and space administration (NASA), is applied to the AFGROW software. Forman and Newman at NASA, De Koning at National Aerospace Laboratory (NLR) and Henriksen at entertainment software association (ESA) developed the elements of the NASGRO crack growth rate equation. It has been implemented in AFGROW [14] as follows.

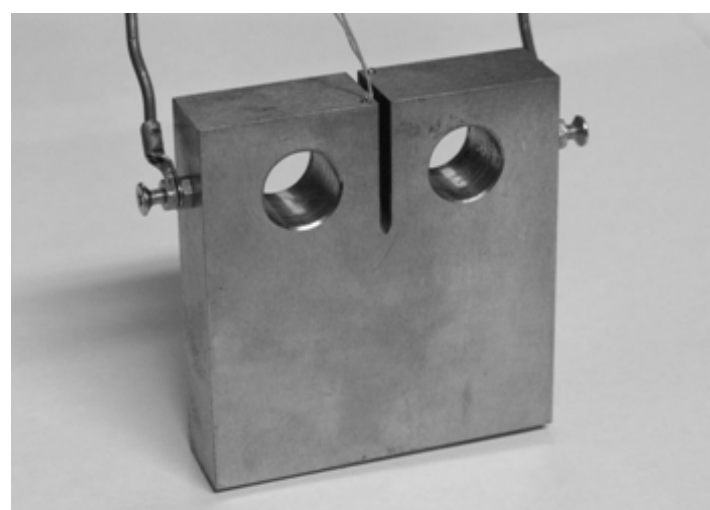

Figure 2. Photograph of connecting wires on standard CT specimen prior to fatigue crack propagation experiment.

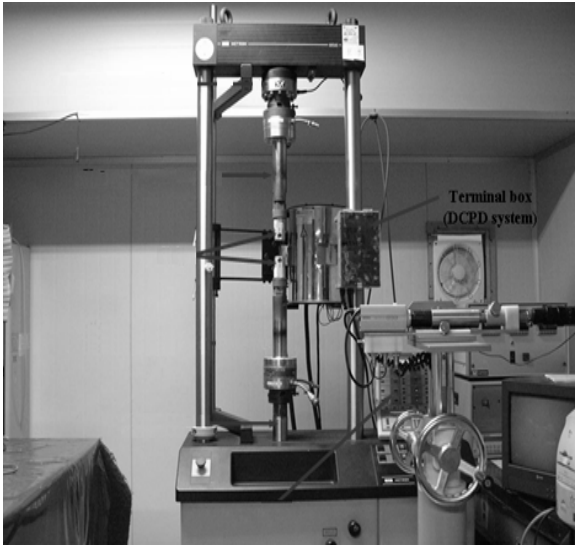

(a)

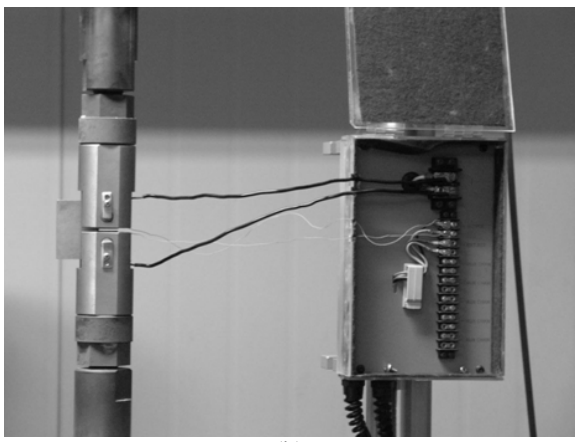

(b)

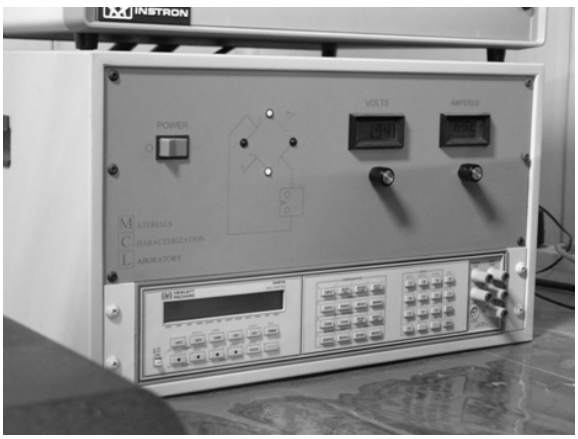

(c)

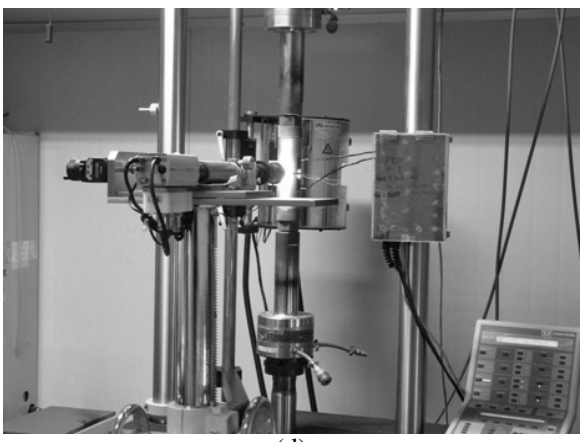

(d)

Figure 3. Equipment for fatigue crack propagation experiment. (a) Apparatus, (b) Connections and terminal box, (c) DCPD system, (d) System for measuring and observing surface cracking. 


$$
\frac{\mathrm{d} a}{\mathrm{~d} N}=C\left[\left(\frac{1-f}{1-R}\right) \Delta K\right]^{m} \frac{\left(1-\frac{\Delta K_{t h}}{\Delta K}\right)^{p}}{\left(1-\frac{K_{\max }}{K_{c r i t}}\right)^{q}}
$$

where $C, m, p$ and $q$ are empirically derived, and

$$
\begin{aligned}
f & =\frac{K_{o p}}{K_{\max }} \\
& =\left\{\begin{array}{cc}
\max \left(A_{0} R+A_{1} R+A_{2} R^{2}+A_{3} R^{3}\right) & R \geq 0 \\
A_{0} R+A_{1} R & -2 \leq R<0 \\
A_{0}-2 A_{1} & R<-2
\end{array}\right\}
\end{aligned}
$$

The coefficients are:

$$
\begin{aligned}
& A_{0}=\left(0.825-0.34 \alpha+0.05 \alpha^{2}\right)\left[\cos \left(\frac{\frac{\pi}{2} \sigma_{\max }}{\sigma_{0}}\right)\right]^{\frac{1}{\alpha}} \\
& A_{1}=(0.415-0.071 \alpha) \sigma_{\max } / \sigma_{0} \\
& A_{2}=1-A_{0}-A_{1}-A_{3} \\
& A_{3}=2 A_{0}+A_{1}-1
\end{aligned}
$$

Here, $\alpha$ is the plane stress/strain constraint factor, and $\sigma_{\max } / \sigma_{0}$ is the ratio of the maximum applied stress to the flow stress. These values have been provided by the NASGRO material database for each material.

$$
\Delta K_{t h}=\Delta K_{0}\left(\frac{a}{a+a_{0}}\right)^{\frac{1}{2}} /\left(\frac{1-f}{1-A_{0}(1-R)}\right)^{\left(1+C_{t h} R\right)}
$$

where

$\Delta K_{0} \quad$ threshold stress intensity range at a

$a \quad$ crack size

$a_{0} \quad$ intrinsic crack size $(0.0015$ in or $0.0000381 \mathrm{~m})$

$C_{t h} \quad$ threshold coefficient

The values for $\Delta K_{0}$ and $C_{t h}$ are provided by the NASGRO material database for each material. The NASGRO equation uses the critical stress intensity factor, $K_{\text {crit }}$ to account for the thickness effects.

$$
\frac{K_{\text {crit }}}{K_{I C}}=1+B_{K} e^{-\left(A_{K} \frac{t}{t_{0}}\right)^{2}}
$$

where:

$C_{I C}$ plane strain fracture toughness (mode I)

$A_{k} \quad$ fit parameter

$B_{k} \quad$ fit parameter

$t$ thickness

$t_{0} \quad$ reference thickness (plane strain condition)
The plane strain condition is:

$$
t_{0}=2.5\left(K_{I C} / \sigma_{V S}\right)^{2}
$$

The values for $K_{I C}, A_{k}$ and $B_{k}$ are provided by the NASGRO material database for each material. Although the plane strain thickness, $\mathrm{t}_{0}$, is defined by Equation (11), $K_{\text {crit }}$ will asymptotically approach $K_{I C}$ as the actual thickness becomes larger than $\mathrm{t}_{0}$.

For part-through cracks, the NASGRO equation uses a variable $K_{I C}$ in place of $K_{\text {crit }}$ The value $K_{I C}$ is a material constant since the developers of the NASGRO equation felt that the $K_{\text {crit }}$ value of a part-through crack is not highly dependent on thickness. The value $K_{c r i t}$, is calculated internally and is only used by AFGROW to determine $\mathrm{d} a / \mathrm{d} N$. It is not used as a failure criterion.

\section{Experimental Results and Estimation of Remaining Lifetime}

The analysis shows the constant amplitude crack propagation curve (see Figure 4). The final crack size is 108.9 $\mathrm{mm}$ and 870000 cycles are needed to reach that point, at which the crane collapses. The simulation using the AFGROW software supplies the constant amplitude crack propagation curve, as shown in Figure 4. The final crack size is $107.4 \mathrm{~mm}$ and 818000 cycles are needed to reach that point, at which the crane will collapse. The curve increases sharply at about 780000 cycles so it is clear that the fatigue crack propagates quickly in that region.

The fatigue crack life should be 30.2 years if the cane is operated for 28800 cycles per year in accordance with the experimental results shown in Figure 5 and it should be 28.4 years if the crane is operated for 28800 cycles per year in accordance with the simulation result shown in Figure 5.

Figure 6 shows that the curve is moderately slow and

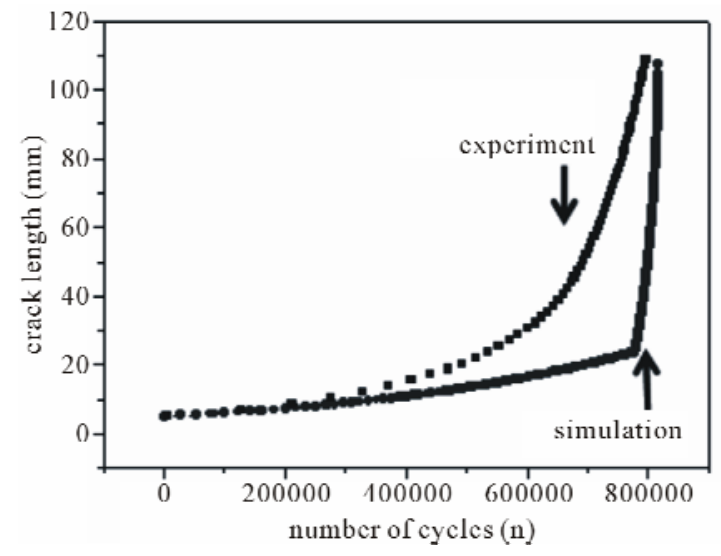

Figure 4. Comparison of experimental data and simulation data on crack propagation vs. number of cycles for main jib. 


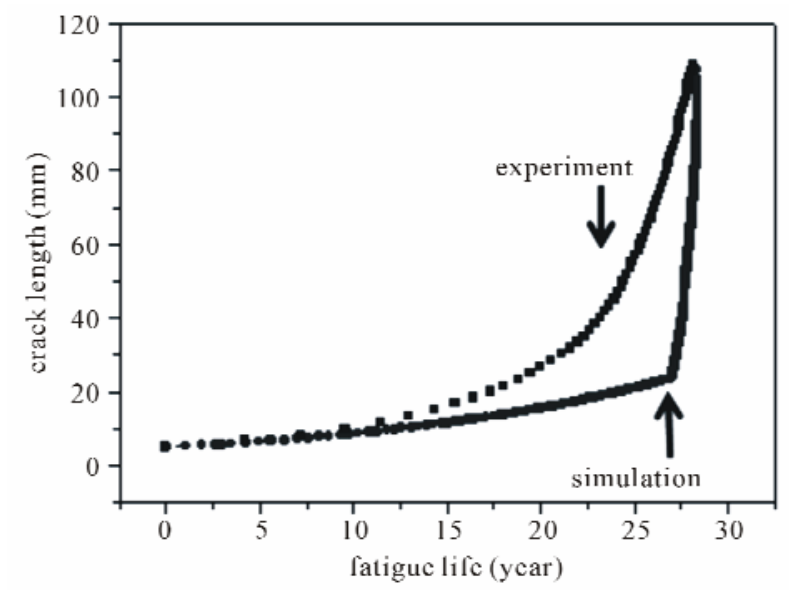

Figure 5. Comparison of experimental data and simulation data on crack length vs. fatigue life for main jib.

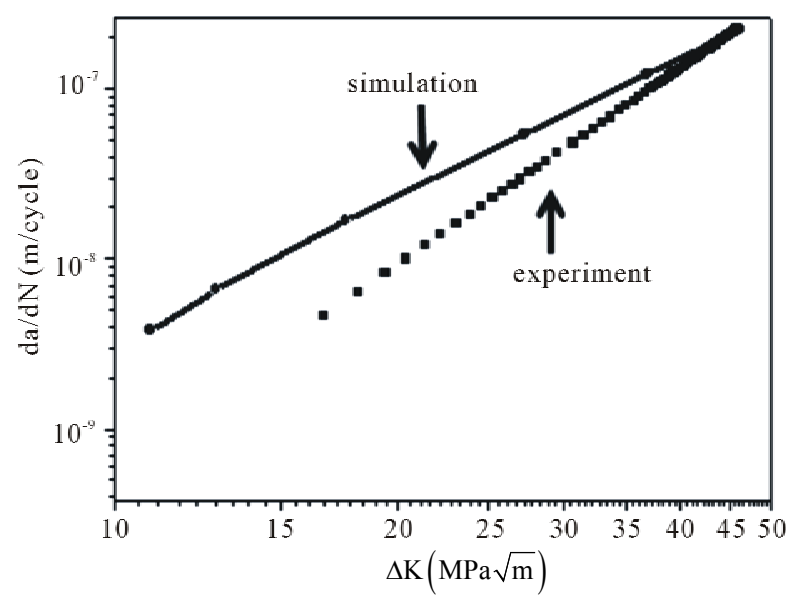

Figure 6. Comparison of experimental data and simulation data for $\mathrm{da} / \mathrm{dN}-\Delta \mathrm{K}$ curve for main jib.

provides a general indication in region II of the crack propagation curves. It is clear that the fatigue crack propagation is not that fast. The remaining life will be 870000 cycles, that is 30.2 years, based on the adaptation of the Paris equation with derived material constants and from the experimental results.

\section{Conclusions}

This study has considered the tests carried out to estimate the remaining life of a level luff crane in use at a port. The crack propagation experiments were performed using an Instron 8516 machine and the results for the fatigue crack propagation in the crane's main jib were derived theoretically.

The conclusions drawn from the experiment of crack propagation analysis were as follows:

1) The material constants $\left(\mathrm{C}=5.11 \times 10^{-11}\right.$ and $\mathrm{m}=$
2.260) which are necessary for the fatigue crack propagation analysis and are key factors in the theoretical calculations were obtained experimentally.

2) The critical size of the crack in the surface of the upper flange of the main jib was almost in accord with the value of $108.9 \mathrm{~mm}$ which was calculated theoretically. Thus, the main jib would collapse when the crack reached its critical value.

3) The theoretical propagating fatigue life calculation took 870000 cycles and the life remaining in the main jib of the crane has been confirmed to be about 30.2 years if the crane undertakes $28800 \mathrm{cy}-$ cles in a year.

4) Furthermore, the conclusions drawn from the crack propagation simulation analysis are as follows.

5) The critical size of the crack in the surface of the upper flange of the main jib was $107.4 \mathrm{~mm}$. The crane should collapse when the crack reaches its critical value.

6) The propagating fatigue life calculation by simulation took 818000 cycles. The remaining life of the main jib of the crane has been confirmed to be about 28.4 years, assuming that the crane performs 28800 cycles per year under constant amplitude loading.

\section{REFERENCES}

[1] D. Wu, Y. Hu and X. Fan, "Visual Simulation for Granular Rocks Crush in Virtual Environment Based on Fractal Geometry," Simulation Modelling Practice and Theory, Vol. 17, No. 7, 2009, pp. 1254-1266. doi:10.1016/j.simpat.2009.04.010

[2] F. Lanoue, A. Vadean and B. Sanschagrin, "Finite Element Analysis and Contact Modelling Considerations of Interference Fits for Fretting Fatigue Strength Calculations," Simulation Modelling Practice and Theory, Vol. 17, No. 10, 2009, pp. 1587-1602. doi:10.1016/j.simpat.2009.06.017

[3] S. Y. Kim, S. S. Kim and H. Choi, "Remaining Life Estimation of a Level Luffing Crane Component by Computer Simulation," Korean Institute of Metals and Materials, Vol. 48, No. 6, 2010, pp. 489-497.

[4] S. Y. Kim, H. S. Bae, Y. H. Lee and M. K. Park, "Computer Simulation for Residual Life Expectancy of a Container Crane Boom Structure," Journal of the Korean Society for Precision Engineering, Vol. 24, No. 9, 2007, pp. 125-128.

[5] C. W. Hur, "A Study on the Design and Life Expectancy of a Double Link Type Level Luffing Jib Crane," Ph.D. Thesis, Department of Mechanical Engineering, Pukyong National University, 2002.

[6] P. C. Paris and F. Erdogan, "A Critical Analysis of Crack 
Propagation Laws," Transaction ASME, Journal of Basic Engineering, Vol. 85, No. 1, 1963, pp. 528-534.

[7] "Structural Analysis and Design Software, STAAD," Proceeding of Research Engineers International, 2004.

[8] Japanese Standards Association, JIS B 8821, "Specification for the Design of Crane Structures," 2004.

[9] JIS B 8831, Japanese Standards Association, "CranesDesign principles for loads and load combinations," 2004.

[10] Federation europeenne De La manutention (FEM Code), "Rules for the Design of Hoisting Appliances," Technical Commission of FEM Section I, 1998.

[11] "Specification for Electric Overhead Traveling Cranes," Crane Manufacturers Association of America Inc., CMAA Specified No. 70, 1988.
[12] ASTM Code, E647-95a, "Standard Test Method for Measurement of Fatigue Crack Growth Rates," American Society for Testing and Materials, 1995.

[13] H. S. Kim and B. W. Ahn, "An Experimental on the Evaluation of Fatigue Crack Propagation of Carbon Steel," Journal of the Korean Society of Mechanical Engineers, Vol. 13, No. 5, 1989, pp. 938-946.

[14] Y. B. Lee and B. D. Oh, "Characteristics of Fatigue Crack Propagations with Respect to the Angles between Rolling and Tensile Loading Directions of Steel Plates," Transactions of the Korean Society of Machine Tool Engineers, Vol. 14, No. 3, 2005, pp. 74-80.

[15] J. A. Harter, "AFGROW Users Guide and Technical Manual,” Air Force Research Laboratory, 2003. 